\title{
EVALUASI KEPUASAN PENGGUNA JASA LABORATORIUM KIMIA PT KRAKATAU STEEL (PERSERO) TBK TAHUN 2012-2013*
}

\author{
Hilda Zaikarina ${ }^{1}$, Erfiani² ${ }^{2}$, I Made Sumertajaya \\ 1Department of Statistics, Bogor Agricultural University (IPB), Indonesia, hirudasan@yahoo.com \\ 2Department of Statistics, Bogor Agricultural University (IPB), Indonesia, erfiani@apps.ipb.ac.id \\ ${ }^{3}$ Department of Statistics, Bogor Agricultural University (IPB), Indonesia, imsjaya@apps.ipb.ac.id \\ ¥corresponding author
}

\section{Indonesian Journal of Statistics and Its Applications \\ Vol 1 No 1 (2017), 24 - 38}

Copyright (c) 2017 Hilda Zaikarina, Erfiani and I Made Sumertajaya. This is an open-access article distributed under the Creative Commons Attribution License, which permits unrestricted use, distribution, and reproduction in any medium, provided the original work is properly cited.

\begin{abstract}
One of the services contained in PT Krakatau Steel (Persero) Tbk is the chemical composition analysis services in the chemistry lab. Management system that will create a well-managed laboratory performance is optimal. Manage standard chemistry laboratory is SNI ISO/IEC 17025. Discussed in this standard laboratory management such as through customer feedback. Laboratory customers selected through stratified random sampling with customer categories as strata, like suppliers, derived from plant and internal processes are not routine. In the research lab result that the customer will be satisfied, including services rendered for Customer Satisfaction Index (CSI) is greater than $70 \%$ with the overall characteristics of the respondents subscription in the laboratory was 11.6 years. Overall the indicators included in the priority importance performance analysis (IPA) and has a value kesenjangan beyond the maximum tolerance through kesenjangan analysis approach is the completeness of laboratory equipment $(\mathrm{F})$ and speed of service $(\mathrm{K})$.
\end{abstract}

Keywords: customer satisfaction index (CSI), gap analysis, importance performance analysis (IPA).

* Received Jun 2017; Accepted Jul 2017; Published online on Oct 2017 


\section{Pendahuluan}

PT Krakatau Steel (Persero) Tbk merupakan salah satu industri baja terbesar di Indonesia dan Asia Tenggara yang juga sebagai sektor penyedia jasa. Industri ini merupakan produsen baja lembaran canai panas dan baja lembaran canai dingin terbesar serta produsen batang kawat baja terbesar kedua di Indonesia. Terdapat sebuah divisi yang berfungsi sebagai pengendali proses produksi di unit-unit produksi, yaitu Divisi Quality Control. Salah satu bentuk pengendalian proses produksi yang dilakukan adalah dengan menguji komposisi kimia proses produksi atau produk akhir di Laboratorium Kimia Bahan Baku atau Bahan Pembantu.

Analisis rutin yang dilakukan di laboratorium kimia antara lain analisis bahan baku, air proses, gas proses, oli dan pelumas, besi spons, pellet, dan baja hasil produksi. Selain analisis rutin, laboratorium kimia melakukan analisis komposisi kimia bahan baku atau bahan pembantu produksi pabrik yang berasal dari pemasok. Hasil analisis komposisi kimia bagi PT. Krakatau Steel menjadi salah satu indikator penerimaan bahan baku atau bahan pembantu dari pemasok. Laboratorium kimia pun menerima jasa analisis dari karyawan PT. Krakatau Steel dan perusahaan lainnya yang sedang meneliti suatu masalah tertentu. Oleh karena itu, pelanggan di laboratorium kimia terdiri dari pemasok, karyawan PT. Krakatau Steel dan perusahaan di luar PT. Krakatau Steel.

Laboratorium kimia perlu memberikan perhatian kepada pelanggan untuk memberikan pelayanan yang optimal dan kualitas yang unggul. Hal ini dapat dilakukan dengan mengatur sistem manajemen di laboratorium kimia. Terdapat sebuah standar yang mengatur manajemen di laboratorium kimia, yaitu SNI ISO/IEC 17025. Salah satu evaluasi manajemen yang dapat dilakukan adalah melalui umpan balik pelanggan menggunakan kuesioner. Laboratorium kimia telah melakukan evaluasi kepuasan, namun tidak dilakukan kepada seluruh pelanggan dan kuesioner yang digunakan hanya mengukur tingkat kinerja dengan tiga kategori respon. Pada penelitian ini evaluasi akan dilakukan kepada seluruh pelanggan dengan mengukur tingkat kinerja, harapan, dan kepentingan pelanggan. Instrumen yang digunakan adalah kuesioner dengan empat kategori respon.

\section{Metodologi}

\subsection{Data dan Instrumen Penelitian}

Data yang digunakan pada penelitian ini adalah data primer yang diperoleh melalui survei oleh peneliti. Survei dilakukan pada 13 Mei 2013 - 11 Juli 2013 di Cilegon, Banten melalui wawancara langsung dan surat elektronik. Responden pada penelitian ini adalah pelanggan yang menggunakan jasa laboratorium kimia PT Krakatau Steel (Persero) Tbk pada Januari 2012 - Juni 2013.

Instrumen pada penelitian ini adalah kuesioner yang dibuat dengan mengembangkan indikator kepuasan lima determinasi kualitas jasa. Menurut Kotler dan Keller (2009), kepuasan (satisfaction) adalah perasaan senang atau kecewa seseorang yang timbul karena membandingkan kinerja yang dipersepsikan (hasil) terhadap ekspektasi. Indikator kepuasan dapat dilihat melalui lima determinasi kualitas jasa berikut: 
1) Wujud (tangible), yaitu penampilan fisik, perlatan, personel, dan bahan komunikasi.

2) Keandalan (reliability), yaitu kemampuan untuk melaksanakan jasa yang dijanjikan dengan andal dan akurat.

3) Daya tanggap (responsiveness), yaitu kesediaan membantu pelanggan dan memberikan layanan tepat waktu.

4) Jaminan (assurance), yaitu pengetahuan dan kemampuan karyawan untuk menunjukkan kepercayaan dan keyakinan.

5) Empati (emphaty), yaitu kondisi memperhatikan dan memberikan perhatian pribadi kepada pelanggan.

Pada penelitian ini, terdapat dua jenis kuesioner yang digunakan, yaitu:

1. Kuesioner untuk mengukur tingkat kinerja dan harapan responden dengan menggunakan skala likert empat kategori respon yang dikembangkan melalui determinasi kualitas jasa. Skala Likert yang juga dinamakan skala summatedratings, adalah salah satu teknik pengukuran sikap yang paling sering digunakan dalam riset pemasaran karena memungkinkan responden untuk mengekspresikan intensitas perasaan mereka (Churchill 2005). Berikut adalah indikator yang diperoleh dengan kode untuk masing-masing indikator.

Tabel 1 Kode indikator peubah kuesioner

\begin{tabular}{clc}
\hline & \multicolumn{1}{c}{ Indikator } & Kode \\
\hline 1 & Kejelasan prosedur pelayanan & $\mathrm{A}$ \\
2 & Kejelasan persyaratan pelayanan & $\mathrm{B}$ \\
3 & Kejelasan petugas unit layanan & $\mathrm{C}$ \\
4 & Kenyamanan lingkungan/sarana fisik unit layanan & $\mathrm{D}$ \\
5 & Kesopanan dan keramahan petugas & $\mathrm{E}$ \\
6 & Kelengkapan alat laboratorium & $\mathrm{F}$ \\
7 & Kemampuan petugas laboratorium & $\mathrm{G}$ \\
8 & Kedisiplinan petugas dalam melayani pelanggan & $\mathrm{H}$ \\
9 & Tanggungjawab petugas unit layanan & $\mathrm{I}$ \\
10 & Administrasi laboratorium & $\mathrm{J}$ \\
11 & Kecepatan pelayanan & $\mathrm{K}$ \\
12 & Respon terhadap keluhan dan saran pelanggan & $\mathrm{L}$ \\
13 & Kepastian jadwal pelayanan & $\mathrm{M}$ \\
14 & Keselamatan, Kesehatan, dan Kerja (K3) & $\mathrm{N}$ \\
15 & Keadilan mendapatkan pelayanan & $\mathrm{O}$ \\
16 & Petugas memperhatikan kepentingan pelanggan & $\mathrm{P}$ \\
\hline
\end{tabular}

2. Kuesioner untuk mengukur tingkat kepentingan dengan cara mengurutkan lima peubah determinasi kualitas jasa dan enam belas indikator sesuai dnegan prioritas kepentingannya.

\subsection{Metode Penarikan Contoh}

Menurut Hadi (2007), pelanggan adalah organisasi atau seseorang yang mempunyai beberapa kepentingan tertentu terhadap suatu produk atau jasa. Objek survei pada penelitian ini adalah pelanggan utama yang menggunakan jasa laboratorium kimia PT Krakatau Steel (Persero) Tbk pada Januari 2012 - Juni 2013. Pelanggan 
utama adalah pelanggan yang menjadi fokus utama di laboratorium kimia, yaitu pelanggan dari PT. Krakatau Steel (Persero) Tbk baik dari analisis rutin proses pabrik maupun analisis tidak rutin, serta perusahaan-perusahaan pemasok PT. Krakatau Steel (Persero) Tbk. Perusahaan luar yang bukan pemasok tidak termasuk pelanggan utama karena bukan bagian utama dari PT. Krakatau Steel (Persero) Tbk.

Responden dipilih sebagian dengan menggunakan metode penarikan contoh berpeluang, yaitu penarikan contoh acak berlapis (stratified random sampling). Scheaffer et al. (1990) mendefinisikan penarikan contoh acak berlapis adalah penarikan contoh dengan membagi populasi ke dalam kelompok yang tidak tumpang tindih kemudian mengambil contoh di setiap kelompok dengan teknik penarikan contoh acak sederhana. Lapisan yang digunakan adalah pelanggan yang berasal dari proses pabrik, tidak rutin, dan pemasok karena proses dan tujuan analisis ketiga kategori tersebut berbeda-beda.

Diperoleh daftar jumlah seluruh pelanggan laboratorium yaitu 116 orang yang terdiri dari 19 orang pelanggan proses pabrik, 47 orang tidak rutin, dan 50 oramg pemasok. Masing-masing pelanggan pada lapisan dipilih secara acak untuk dijadikan responden dengan menggunakan metode penarikan contoh acak sederhana (simple random sampling). Menurut Scheaffer et al. (1990), jika contoh sebesar $n$ diambil dari populasi sebesar $\mathrm{N}$ dengan peluang yang sama disebut sebagai penarikan contoh acak sederhana. Sejumlah $n$ contoh diperoleh menggunakan metode Slovin dengan asumsi biaya dan ragam masing-masing populasi lapisan adalah sama. Berikut adalah rumus metode Slovin:

$$
\mathrm{n}=\frac{\mathrm{N}}{1+\mathrm{Ne}^{2}}
$$

Keterangan :

$\mathrm{n} \quad$ = banyaknya contoh

$\mathrm{N}$ = banyaknya populasi

e = batas kesalahan

Batas kesalahan yang digunakan adalah $10 \%$. Jumlah contoh acak untuk lapisan tidak rutin adalah 32 orang dan pemasok 34 orang. Responden yang berasal dari proses pabrik tidak dipilih secara acak, melainkan diambil keseluruhan sebanyak 19 orang (sensus), dengan demikian total responden yang diperoleh adalah 85 orang. Dari 85 orang hanya diperoleh 5 orang responden dari metode wawancara langsung dan 12 orang dari surat elektronik yang mengisi kuesioner tingkat kepentingan dengan benar, hal ini menyebabkan tingkat kepentingan diukur dari 17 orang tersebut.

\subsection{Analisis Data}

Tahapan yang dilakukan dalam penelitian ini adalah :

1. Melakukan uji validitas dan reliabilitas kuesioner. Validitas diukur dengan membandingkan nilai korelasi pertanyaan masing-masing indikator dengan total keseluruhan pertanyaan indikator. 
keterangan:

$$
r_{i}=\frac{\sum_{j=1}^{n}\left(x_{i j}-\bar{x}_{i}\right)\left(t_{j}-\bar{t}\right)}{\sqrt{\sum_{j=1}^{n}\left(x_{i j}-\bar{x}_{i}\right)^{2} \sum_{j=1}^{n}\left(t_{j}-\bar{t}\right)^{2}}}
$$

$x_{i j}=$ skor responden ke-j pada butir pertanyaan $\mathrm{i}$

$\bar{x}_{i}=$ rata-rata skor butir pertanyaan $\mathrm{i}$

$\mathrm{t}_{\mathrm{j}} \quad=$ total skor seluruh pertanyaan untuk responden ke-j

$\bar{t}=$ rata-rata total skor

$r_{i}=$ korelasi antara butir pertanyaan ke-i dengan total skor

Pengujian reliabilitas dapat dilakukan dengan internal consistency teknik cronbach alpha.

$$
r_{i}=\frac{k}{(k-1)}\left[1-\frac{\sum s_{i}^{2}}{s_{t}^{2}}\right]
$$

Keterangan :

$\mathrm{r}_{\mathrm{i}} \quad=$ nilai cronbach alpha butir pertanyaan ke-i

$\mathrm{k} \quad=$ banyaknya butir pertanyaan

$\sum s_{i}^{2} \quad=$ ragam skor butir pertanyaan ke-i

$s_{t}^{2}=$ ragam skor total pertanyaan.

2. Analisis karakteristik pengguna jasa laboratorium kimia menggunakan statistika deskriptif.

3. Mengukur tingkat kepuasan konsumen terhadap labarotorium kimia menggunakan indeks kepuasan konsumen.

Menurut Irawan (2002), indeks kepuasan konsumen atau Customer Satisfaction Index (CSI) dapat digunakan sebagai acuan untuk menentukan tujuan di masa yang akan datang. Indeks ini diperlukan karena proses pengukuran kepuasan pelanggan bersifat kontinu. Terdapat empat langkah dalam perhitungan CSI yaitu:

1) Menentukan Mean Importance Score $(\bar{Y})$ dan Mean Satisfaction Score $(\bar{X})$. Nilai ini berasal dari rata-rata tingkat kepentingan dan kinerja tiap responden:

$\bar{Y}=\frac{\sum_{\mathrm{i}=1}^{\mathrm{n}} \mathrm{Y}_{\mathrm{i}}}{\mathrm{n}}$ dan $\overline{\mathrm{X}}=\frac{\sum_{\mathrm{i}=1}^{\mathrm{n}} \mathrm{X}_{\mathrm{i}}}{\mathrm{n}}$

keterangan :

$\mathrm{n}=$ jumlah responden

$Y_{i}=$ nilai kepentingan atribut ke $\mathrm{i}$

$X_{i}=$ nilai kinerja atribut ke $\mathrm{i}$

2) Membuat faktor pembobot atau weight factor (WF). Bobot ini diperoleh melalui peringkat dari prioritas kepentingan masing-masing atribut pertanyaan. Bobot dapat dilihat pada Lampiran 3.

3) Membuat skor pembobot atau weighting score (WS). Bobot ini diperoleh dari perkalian antara faktor pembobot dengan rata-rata tingkat kepuasan (Mean Satisfaction Score atau MSS)

$$
\mathrm{WS}_{\mathrm{i}}=\mathrm{WF}_{\mathrm{i}} \times \mathrm{MSS}_{\mathrm{i}}
$$


keterangan :

$\mathrm{WS}_{\mathrm{i}}=$ skor pembobot ke-i

$\mathrm{WF}_{\mathrm{i}}=$ faktor pembobot ke-i

$\mathrm{MSS}_{\mathrm{i}}=$ rata-rata tingkat kepuasan ke-i

4) Mengitung indeks kepuasan konsumen. Skala kepuasan konsumen yang umum dipakai dalam interpretasi indeks adalah skala nol sampai seratus. Perhitungan CSI :

$$
\mathrm{CSI}=\frac{\sum_{\mathrm{i}=1}^{\mathrm{n}} \mathrm{WS}_{\mathrm{i}}}{\mathrm{k}} \times 100 \%
$$

$\mathrm{k}$ adalah nilai maksimal skor kepuasan pada penelitian ini yaitu 4 .

4. Mengevaluasi atribut-atribut laboratorium kimia menggunakan Importance Performance Analysis (IPA). Menurut Nasution (2004), metode IPA dilakukan melalui pengukuran tingkat kesesuaian. Tingkat kesesuaian merupakan perbandingan skor kinerja dengan skor kepentingan. Tingkat kesesuaian inilah yang akan menentukan urutan prioritas faktor yang mempengaruhi kepuasan pelanggan. Tingkat pelaksanaan kinerja dinotasikan dengan $\mathrm{X}$ dan harapan konsumen dinotasikan dengan Y. Langkah-langkah untuk metode IPA adalah sebagai berikut:

1. Menentukan $\bar{X}_{i}$ dan $\bar{Y}_{i}$ yang diperoleh dari

$\mathrm{n}$ adalah jumlah responden.

$$
\bar{X}_{i}=\frac{\sum X_{i}}{n} \operatorname{dan} \bar{Y}_{i}=\frac{\sum Y_{i}}{n},
$$

2. Membuat diagram kartesius dengan sumbu mendatar $(X)$ diisi oleh skor kinerja dan sumbu tegak (Y) diisi oleh skor kepentingan.

3. Menentukan $\overline{\bar{X}}$ dan $\overline{\bar{Y}}$ sebagai titik potong sumbu $\mathrm{X}$ dan $\mathrm{Y}$ yang diperoleh dari

$$
\overline{\bar{X}}=\frac{\sum \bar{X}_{i}}{k} \text { dan } \overline{\bar{Y}}=\frac{\sum \bar{Y}_{i}}{k},
$$

$\mathrm{k}$ adalah banyaknya atribut atau fakta yang mempengaruhi kepuasan pelanggan.

Kepentingan

$$
\overline{\bar{Y}} \begin{array}{l|l|l}
\text { I } & \text { II } \\
\text { Prioritas Utama } & \text { Pertahankan Prestasi } \\
\cline { 2 - 3 } & \text { III } & \text { IV } \\
\cline { 2 - 3 } & \text { Prioritas Rendah } & \bar{X} \\
\end{array}
$$

Gambar 1 Diagram kartesius keluaran metode IPA keterangan :

I : Menunjukkan indikator yang dianggap penting oleh pelanggan namun kinerja yang dirasakan masih rendah.

II : Menunjukkan kinerja dari indikator sudah sesuai dnegan tingkat kepentingan yang tinggi sehingga indikator ini harus dipertahankan.

III : Menunjukkan indikator yang kurang penting bagi pelanggan dan pelaksanaanya biasa saja. Artinya dianggap kurang penting dan kurang memuaskan. 
IV : Menunjukkan indikator yang mempengaruhi pelanggan kurang penting namun pelaksanaannya berlebihan.

5. Mengukur kesenjangan antara jasa yang dirasakan dan yang diharapkan oleh pelanggan menggunakan analisis kesenjangan (gap analysis). Secara harfiah kesenjangan mengidentifikasi adanya suatu perbedaan (disparity) antara satu hal dengan yang lainnya. Salah satu kesenjangan dalam model Parasuraman, Zeithalm, dan Berry (1995) adalah kesenjangan dalam pelayanan yang dirasakan, yaitu perbedaan persepsi antara jasa yang dirasakan dan yang diharapkan oleh pelanggan.

Kesenjangan = jasa yang diharapkan - jasa yang diterima

Setelah diperoleh nilai kesenjangan, dicari nilai rataan kesenjangan dari masingmasing kategori $\left(\bar{y}_{i}\right)$. Akan ditentukan batas toleransi maksimal dari nilai kesenjangan tersebut dari rumus berikut:

keterangan:

$$
\bar{y}_{i}+t_{\frac{\alpha}{2}} S_{\bar{y}_{i}}
$$

$\bar{y}_{i}=$ nilai rataan kesenjangan masing-masing kategori

$S_{\bar{y}_{i}}=$ nilai standar error dari rataan kesenjangan masing-masing kategori.

\section{Hasil dan Pembahasan}

\subsection{Karakteristik Demografi Pelanggan}

Berdasarkan hasil survei diperoleh informasi pelanggan laboratorium kimia memliki karakteristik sebagai berikut:

Tabel 2 Karakteristik pelanggan laboratorium kimia

\begin{tabular}{|c|c|c|c|c|c|c|}
\hline \multirow{2}{*}{$\begin{array}{c}\text { Kateg } \\
\text { ori }\end{array}$} & \multicolumn{3}{|c|}{ Usia (tahun) } & \multicolumn{3}{|c|}{$\begin{array}{c}\text { Lama } \\
\begin{array}{c}\text { Berlanggana } \\
\mathrm{n} \text { (tahun) }\end{array} \\
\end{array}$} \\
\hline & $\begin{array}{c}\mathrm{Mi} \\
\mathrm{n}\end{array}$ & $\begin{array}{c}\mathrm{Ma} \\
\mathrm{x}\end{array}$ & $\begin{array}{l}\text { Rat } \\
\text { aan }\end{array}$ & $\begin{array}{c}\mathrm{Mi} \\
\mathrm{n}\end{array}$ & $\begin{array}{c}\mathrm{Ma} \\
\mathrm{x}\end{array}$ & $\begin{array}{c}\text { Ra } \\
\text { taa } \\
\mathrm{n}\end{array}$ \\
\hline $\begin{array}{l}\text { Prose } \\
\mathbf{s} \\
\text { pabri } \\
\text { k }\end{array}$ & 22 & 12 & $\begin{array}{c}38.7 \\
4\end{array}$ & 1 & 25 & 11 \\
\hline $\begin{array}{l}\text { Tidak } \\
\text { rutin }\end{array}$ & 25 & 55 & $\begin{array}{c}48.3 \\
4\end{array}$ & 3 & 30 & $\begin{array}{l}14 . \\
06\end{array}$ \\
\hline $\begin{array}{l}\text { Pema } \\
\text { sok }\end{array}$ & 20 & 74 & $\begin{array}{c}43.0 \\
9\end{array}$ & 1 & 28 & $\begin{array}{c}9.6 \\
2\end{array}$ \\
\hline $\begin{array}{l}\text { Kesel } \\
\text { uruha } \\
\text { n }\end{array}$ & 20 & 74 & $\begin{array}{c}44.0 \\
9\end{array}$ & 1 & 30 & $\begin{array}{c}11 . \\
6\end{array}$ \\
\hline
\end{tabular}

Berdasarkan Tabel 3, secara keseluruhan usia pelanggan minimal adalah 20 tahun dengan usia paling tua adalah 74 tahun. Rata-rata lama berlanggan secara keseluruhan adalah 11.6 tahun dengan rata-rata paling besar yaitu kategori tidak rutin sebesar 14.06 tahun. Jabatan dari pelanggan yang berasal dari proses pabrik 
mayoritas adalah operator, sedangkan jabatan pelanggan yang berasal dari tidak rutin dan pemasok cukup beragam. Diagram pie jabatan responden secara keseluruhan dapat dilihat pada Lampiran 2.

\subsection{Analisis Pemenuhan Harapan dengan Kinerja Menggunakan Pendekatan Indeks Kepuasan Konsumen}

Menurut Kotler dan Keller (2009), kepuasan (satisfaction) adalah perasaan senang atau kecewa seseorang yang timbul karena membandingkan kinerja yang dipersepsikan produk (hasil) terhadap ekspektasi. Indeks kepuasan konsumen atau customer satisfaction index (CSI) digunakan untuk mengukur kepuasan pelanggan. Dibutuhkan faktor pembobot untuk mendapatkan nilai CSI. Faktor pembobot pada perhitungan CSI diperoleh dari 17 responden yang memberikan urutan prioritas kepentingan pada peubah determinasi kualitas jasa dan masing-masing indikator. Faktor pembobot dapat dilihat pada Lampiran 3, berikut adalah skor CSI yang diperoleh:

Tabel 2 Skor CSI setiap kategori

\begin{tabular}{|c|c|c|c|}
\hline No & Kategori & $\begin{array}{l}\text { Skor } \\
\text { CSI }\end{array}$ & $\begin{array}{c}\text { Standar } \\
\text { Error } \\
\text { (SE) }\end{array}$ \\
\hline$\overline{1}$ & $\begin{array}{l}\text { Proses } \\
\text { pabrik }\end{array}$ & $\begin{array}{l}78.84 \\
\%\end{array}$ & $16.22 \%$ \\
\hline 2 & Tidak rutin & $\begin{array}{l}72.57 \\
\%\end{array}$ & $11.39 \%$ \\
\hline \multirow[t]{2}{*}{3} & Pemasok & $\begin{array}{l}74.10 \\
\%\end{array}$ & $8.02 \%$ \\
\hline & Keseluruhan & $\begin{array}{l}74.58 \\
\% \\
\end{array}$ & $9.43 \%$ \\
\hline
\end{tabular}

Berdasarkan Tabel 4, seluruh kategori termasuk dalam kondisi puas terhadap laboratorium kimia karena memiliki skor di atas $70 \%$. Skor CSI pelanggan proses pabrik paling besar dibandingkan kategori yang lain yaitu sebesar $78.84 \%$ sedangkan pelanggan tidak rutin memiliki tingkat kepuasan yang paling rendah yaitu sebesar $72.57 \%$. Hal ini terjadi karena proses analisis dan prosedur yang dilakukan antar kategori berbeda. Pelanggan yang berasal dari proses pabrik mengirimkan langsung contoh yang diuji ke dalam laboratorium dan hasilnya langsung diperoleh hari itu juga. Berbeda dengan tidak rutin maupun pemasok yang proses analisisnya melalui prosedur yang berbeda. Pada pelanggan tidak rutin, contoh diberikan pada petugas penerima contoh, kemudian contoh dibawa ke bagian petugas analisis. Hasil pengujian diberikan kepada petugas administrasi untuk dipersiapkan hasil pengujiannya lalu diserahkan kembali ke petugas penerima contoh. Pelanggan akan kembali beberapa hari kemudian setelah sertifikat atau hasil pengujian berada pada petugas penerima contoh. Sama halnya dengan pemasok yang membutuhkan waktu beberapa hari sebelum menerima sertifikat ataupun hasil pengujian, namun pemasok tidak berinteraksi langsung dengan laboratorium. 
Berdasarkan evaluasi dari penelitian ini, kecepatan perolehan hasil pengujian menjadi kendala pada kategori tidak rutin dan pemasok, namun secara keseluruhan pelanggan laboratorium termasuk dalam kategori puas karena skor CSI berada di atas nilai $70 \%$. Hal ini berdasarkan kriteria nilai kepuasan PT Sucofindo dalam melakukan survei kepuasan pelanggan.

Tabel 3 Kriteria nilai indeks kepuasan konsumen

\begin{tabular}{ll}
\hline Nilai CSI & Kriteria CSI \\
\hline $\mathbf{8 1} \%$ & - Sangat Puas \\
$\mathbf{1 0 0 \%}$ & \\
$\mathbf{6 6 \%}-\mathbf{8 0 \%}$ & Puas \\
$\mathbf{5 1} \%-\mathbf{6 5 \%}$ & Cukup Puas \\
$\mathbf{3 5 \% - 5 0 \%}$ & Kurang Puas \\
$\mathbf{0 \% - 3 4 \%}$ & Tidak Puas \\
\hline \multicolumn{2}{c}{ Sumber : Oktaviani (2006) }
\end{tabular}

\subsection{Analisis Tingkat Kepentingan dengan Capaian Kinerja Setiap Indikator Menggunakan Importance Performance Analysis}

Indikator-indikator pertanyaan pada kuesioner diukur tingkat kinerja dan kepentingannya. Kedua hal tersebut akan dibandingkan melalui diagram pencar dengan kepentingan sebagai sumbu $Y$ dan kinerja sebagai sumbu $X$. Plot pada diagram pencar diperoleh dari koordinat $X$ dan $Y$ masing-masing indikator. Berdasarkan hasil penelitian diperoleh indikator-indikator yang perlu diperhatikan pada masing-masing kuadran sebagai berikut:

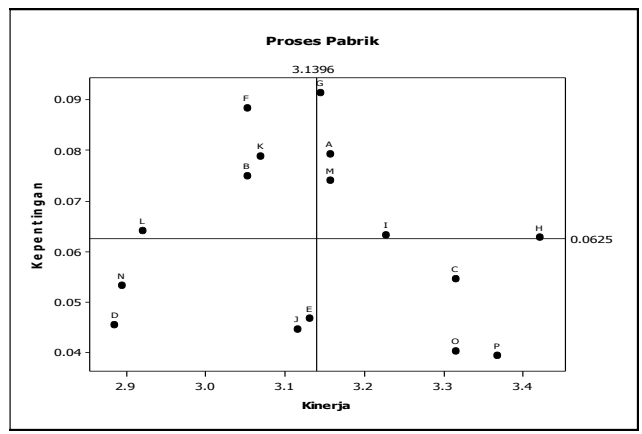

Gambar 2 Keluaran diagram pencar kategori proses pabrik

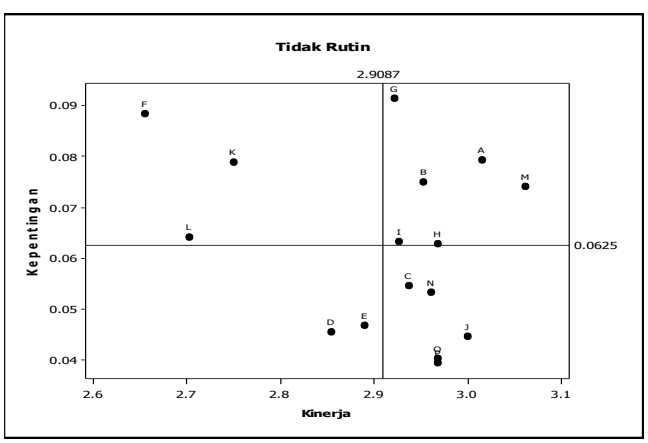

Gambar 3 Keluaran diagram pencar kategori tidak rutin 


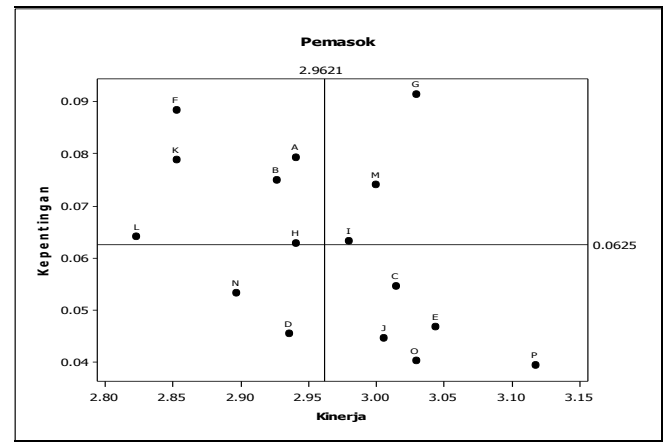

Gambar 4 Keluaran diagram pencar kategori pemasok

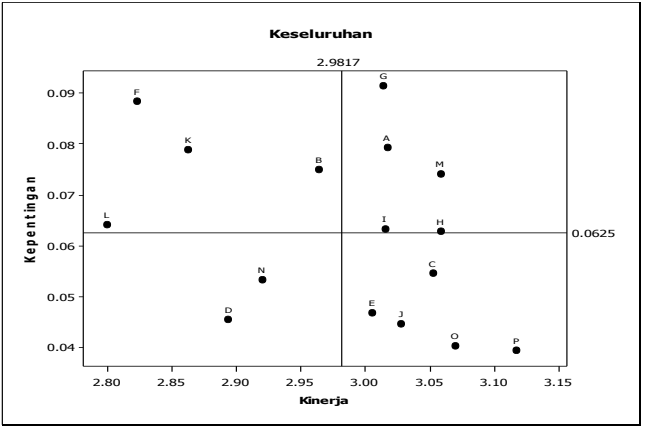

Gambar 5 Keluaran diagram pencar keseluruhan responden

Jika dirangkum berdasarkan keluaran diagram pencar di atas diperoleh indikator-indikator berikut yang masuk ke dalam masing-masing kuadran:

Tabel 5 Ringkasan indikator keluaran diagram pencar

\begin{tabular}{|c|c|c|c|c|}
\hline Kategori & $\begin{array}{l}\text { Kuadran } \\
\text { I }\end{array}$ & $\begin{array}{l}\text { Kuadran } \\
\text { II }\end{array}$ & $\begin{array}{l}\text { Kuadran } \\
\text { III }\end{array}$ & $\begin{array}{l}\text { Kuadran } \\
\text { IV }\end{array}$ \\
\hline $\begin{array}{l}\text { Proses } \\
\text { Pabrik } \\
\text { Tidak Rutin }\end{array}$ & $\begin{array}{l}\mathrm{B}, \mathrm{F}, \mathrm{K}, \\
\text { dan } \mathrm{L} \\
\mathrm{F}, \mathrm{K} \text {, dan } \\
\mathrm{L}\end{array}$ & $\begin{array}{l}\mathrm{A}, \mathrm{G}, \mathrm{H}, \\
\mathrm{I}, \text { dan } \mathrm{M} \\
\mathrm{A}, \mathrm{B}, \mathrm{G}, \\
\mathrm{H}, \mathrm{I} \text {, dan } \\
\mathrm{M}\end{array}$ & $\begin{array}{l}\mathrm{D}, \mathrm{E}, \mathrm{J}, \\
\text { dan N } \\
\mathrm{D} \text { dan } \mathrm{E}\end{array}$ & $\begin{array}{l}\mathrm{C}, \quad \mathrm{O}, \\
\text { dan } \mathrm{G} \\
\mathrm{C}, \mathrm{J}, \mathrm{N}, \\
\mathrm{O}, \operatorname{dan} \mathrm{P}\end{array}$ \\
\hline Pemasok & $\begin{array}{l}A, B, F, \\
H, K \text {, dan } \\
L\end{array}$ & $\begin{array}{l}\text { G, I, dan } \\
M\end{array}$ & $\mathrm{D}$ dan $\mathrm{N}$ & $\begin{array}{l}\text { C, E, J, } \\
\text { O, dan P }\end{array}$ \\
\hline Kes & $\begin{array}{l}\mathrm{B}, \mathrm{F}, \mathrm{K}, \\
\operatorname{dan} \mathrm{L}\end{array}$ & $\begin{array}{l}\mathrm{A}, \mathrm{G}, \mathrm{H}, \\
\mathrm{I}, \text { dan } \mathrm{M}\end{array}$ & $\mathrm{D}$ dan $\mathrm{N}$ & $\begin{array}{l}\text { C, E, J, } \\
O \text {, dan } P\end{array}$ \\
\hline
\end{tabular}


Kuadran I berarti indikator memiliki tingkat kepentingan tinggi namun kinerja yang dirasakan pelanggan masih rendah. Indikator ini merupakan fokus utama yang harus segera diperbaiki oleh laboratorium agar kepuasan pelanggan dapat meningkat sehingga loyalitas pelanggan terjaga. Indikator yang konsisten muncul pada indikator ini adalah kelengkapan alat laboratorium $(F)$, kecepatan pelayanan $(K)$, serta respon terhadap keluhan dan saran pelanggan (L).

Kelengkapan alat bagi pelanggan menjadi prioritas utama, sehingga apabila terdapat alat yang rusak harus segera diperbaiki dan dilakukan peremajaan alat di laboratorium. Indikator lain yaitu kecepatan pelayanan di laboratorium pun perlu ditingkatkan karena indikator ini yang paling banyak dikeluhkan oleh pelanggan. Proses perolehan hasil pengujian setiap kategori berbeda-beda. Setiap hasil pengujian pada kategori proses pabrik disampaikan lewat telepon, dan soft copy melalui komputer di laboratorium lalu dikirimkan ke komputer lain (MES). Pelanggan proses pabrik menginginkan setelah hasil analisis sudah keluar seharusnya langsung dikirimkan langsung kepada mereka. Pada kategori tidak rutin dan pemasok, hasil pengujian yang diterima dalam bentuk hard copy (sertifikat). Waktu yang dibutuhkan sampai dengan sertifikat diterima oleh pelanggan tergantung dari kategori contoh yang dibawa, yaitu penting atau tidak. Pada prosesnya, responden mengeluhkan terkadang waktu dikeluarkan sertifikat tidak sesuai waktu yang disepakati. Laboratorium harus meningkatkan kecepatan dalam melayani pelanggan agar sertifikat dapat diterima pelanggan tepat pada waktunya. Respon terhadap keluhan dan saran perlu diperbaiki. Ketika pelanggan menyampaikan keluhan ataupun saran pihak laboratoium harus segera menindaklanjutinya dengan cepat.

Indikator kejelasan persyaratan pelayanan (B) termasuk prioritas utama yang harus segera diperbaiki menurut kategori proses pabrik dan pemasok. Pada kategori proses pabrik, rataan lama berlangganan dengan laboratorium adalah 11 tahun. Lama waktu berlangganan cukup lama tersebut seharusnya persyaratan pelayanan sudah jelas, namun jika dilihat responden yang menjawab kurang puas hanya $10.5 \%$ responden dengan salah satunya memiliki harapan yang kurang tinggi terhadap indikator ini. Pada kategori pemasok waktu lama berlangganan yaitu 9.62 tahun. Terdapat $11.8 \%$ responden menjawab tidak puas dengan $5.9 \%$ responden yang memiliki harapan kurang tinggi. Indikator kejelasan prosedur pelayanan (A) dan kedisplinan petugas dalam melayani pelanggan $(\mathrm{H})$ menjadi prioriats utama untuk segera diperbaiki pada kategori pemasok.

Indikator-indikator yang berada pada kuadran II menunjukkan kinerja yang diberikan oleh laboratorium sudah sesuai dengan kepentingan pelanggan. Indikator pada kuadran ini masih perlu ditingkatkan kembali kinerjanya namun setelah dilakukan perbaikan pada tiga kuadran lainnya. Secara konsisten indikator kemampuan petugas laboratorium (G), tanggung jawab petugas unit layanan (I), dan kepastian jadwal pelayanan (M) muncul pada kuadran ini. Terdapat tambahan indikator kejelasan prosedur pelayanan $(A)$ dan kedisplinan petugas dalam melayani pelanggan $(H)$ pada kategori proses pabrik dan tidak rutin. Indikator kejelasan persyaratan pelayanan (B) pun dianggap sudah sesuai dengan harapan kategori tidak rutin.

Kuadran III berarti prioritas rendah, yaitu pelanggan tidak memiliki kepentingan yang tinggi dan memperoleh kinerja yang tidak tinggi juga. Indikator kenyamanan 
lingkungan/sarana fisik unit layanan (D) secara konsisten muncul pada kuadran ini. Hal ini terjadi karena pelanggan datang ke laboratorium tidak untuk berlama-lama bahkan ada yang hanya mengantarkan contoh saja, jadi kenyamanan sarana fisik tidak terlalu diperhatikan walaupun pada kinerjanya tidak cukup memuaskan. Pada kategori pemasok muncul indikator keselamatan, kesehatan, serta kerja $(\mathrm{N})$ sebagai indikator prioritas rendah, sedangkan pada tidak rutin indikator kesopanan dan keramahan petugas (E) yang muncul. Pada kategori proses pabrik keduanya muncul dengan tambahan indikator administrasi laboratorium $(\mathrm{J})$ karena pada teknisnya kategori ini tidak membutuhkan administrasi yang seperti kategori lainnya.

Wilayah terakhir adalah kuadran IV yang berarti kepentingan pelanggan tidak tinggi namun kinerja yang dirasakan cukup tinggi (berlebihan). Secara konsisten indikator kejelasan petugas unit pelayanan (C) dan keadilan mendapat pelayanan (O) muncul pada kuadran ini. Hal ini menunjukkan laboratorium sudah cukup adil dalam melayani pelanggan dengan petugas yang sudah jelas. Indikator kemampuan petugas laboratorium (G) muncul untuk kategori proses pabrik. Sedangkan kategori tidak rutin, muncul indikator administrasi laboratorium $(\mathrm{J})$, keselamatan, kesehatan, serta kerja $(\mathrm{N})$, dan petugas memperhatikan kepentingan pelanggan $(\mathrm{P})$.

\subsection{Kesenjangan Kinerja dengan Harapan Pelanggan Melalui Pendekatan Analisis Kesenjangan}

Berikut merupakan selisih yang diperoleh antara harapan dengan kinerja melalui pendakatan analisis kesenjangan.

Tabel 7 Nilai kesenjangan harapan dan kinerja masing-masing kategori

\begin{tabular}{ccccc}
\hline Indikator & $\begin{array}{c}\text { Proses } \\
\text { Pabrik }\end{array}$ & $\begin{array}{c}\text { Tidak } \\
\text { rutin }\end{array}$ & Pemasok & $\begin{array}{c}\text { Keseluruhan } \\
\text { Responden }\end{array}$ \\
\hline A & 0.21053 & 0.18750 & 0.36765 & 0.26471 \\
B & 0.18421 & 0.14063 & 0.33824 & 0.22941 \\
C & 0.21053 & 0.40625 & 0.47059 & 0.38824 \\
D & 0.37719 & 0.36458 & 0.48039 & 0.41373 \\
E & 0.44737 & 0.53125 & 0.54412 & 0.51765 \\
F & 0.68421 & 1.09375 & 0.85294 & 0.90588 \\
G & 0.26316 & 0.64063 & 0.55147 & 0.52059 \\
H & 0.36842 & 0.56250 & 0.76471 & 0.60000 \\
I & 0.52632 & 0.64583 & 0.71569 & 0.64706 \\
J & 0.25263 & 0.48125 & 0.65294 & 0.49882 \\
K & 0.52632 & 0.92708 & 0.78431 & 0.78039 \\
L & 0.36842 & 0.67188 & 0.57353 & 0.56471 \\
M & 0.52632 & 0.46875 & 0.61765 & 0.54118 \\
N & 0.75000 & 0.43750 & 0.77206 & 0.64118 \\
$\mathbf{O}$ & 0.52632 & 0.68750 & 0.64706 & 0.63529 \\
P & 0.26316 & 0.62500 & 0.52941 & 0.50588 \\
\hline
\end{tabular}

Batas toleransi diperoleh dari kesenjangan tersebut, dibuat selang dari rataan kesenjangan masing-masing indikator dengan batas maksimum yang menjadi batas 
tolereansi. Nilai $\alpha$ yang digunakan sebesar 5\%. Berikut adalah ringkasan rataan, ragam, dan batas toleransi yang diperoleh :

Tabel 8 Nilai rataan dan batas toleransi kesenjangan setiap kategori

\begin{tabular}{llcc}
\hline No & Kategori & Rataan & $\begin{array}{c}\text { Batas } \\
\text { Toleransi }\end{array}$ \\
\hline $\mathbf{1}$ & Proses & 0.4053 & 0.7442 \\
& pabrik & & \\
$\mathbf{2}$ & Tidak rutin & 0.5545 & 0.5508 \\
$\mathbf{3}$ & Pemasok & 0.6039 & 0.6041 \\
\hline & Keseluruhan & 0.5409 & 0.5410 \\
\hline
\end{tabular}

Berdasarkan perhitungan pada Tabel 7 diperoleh batas toleransi maksimal kesenjangan pada masing-masing kategori. Pada kategori proses pabrik terdapat satu indikator yang berada di luar batas toleransi maksimal yaitu indikator keselamatan, kesehatan, dan kerja $(\mathrm{N})$, namun indikator ini berada pada kuadran III yang termasuk prioritas rendah, artinya walaupun indikator $\mathrm{N}$ berada pada kesenjangan yang tinggi, indikator ini bukan termasuk indikator yang penting. Indikator-indikator yang termasuk prioritas utama pada kategori ini masih berada pada batas maksimal toleransinya. Hal ini menunjukkan bahwa indikator $B, F, K$, dan $L$ memang memiliki nilai harapan yang rendah bagi kategori proses pabrik sekalipun indikator ini termasuk hal yang penting menurut rataan tingkat kepentingan seluruh responden.

Pada kategori tidak rutin indikator yang berada di luar batas adalah kelengkapan alat laboratorium (F), kecepatan pelayanan (K), dan respon terhadap keluhan dan saran pelanggan $(\mathrm{L})$. Indikator ini berada pada prioritas utama yang harus segera diperbaiki, hal ini menekankan alat-alat di laboratorium harus segera diperbaiki. Indikator lainnya yang berada di luar batas toleransi adalah kemampuan petugas laboratorium (G), kedisplinan petugas dalam melayani pelanggan $(\mathrm{H})$, tanggung jawab petugas unit layanan (I), keadilan mendapat pelayanan (O), dan petugas memperhatikan kepentingan pelanggan (P). Indikator $\mathrm{G}, \mathrm{H}$, dan I berada pada kuadran II sedangkan $\mathrm{O}$ dan $\mathrm{P}$ berada pada kuadran IV. Indikator-indikator ini perlu ditingkatkan juga kinerjanya namun setelah indikator pada kuadran I yang berada di luar batas toleransi telah diperbaiki.

Pada kategori pemasok indikator yang berada di luar batas toleransi adalah kelengkapan alat laboratorium ( $F$ ), kedisplinan petugas dalam melayani pelanggan $(H)$, kecepatan pelayanan $(K)$. Ketiga indikator $F, H$, dan $\mathrm{K}$ termasuk pada prioritas utama dan nilai kesenjangannya berada di luar batas toleransi maksimal. Hal ini menyebabkan ketiga indikator tersebut harus segera ditindaklanjuti oleh pihak laboratorium. Berbeda dengan indikator keselamatan, kesehatan, serta kerja $(\mathrm{N})$ yang termasuk pada prioritas rendah, hal ini menunjukkan bahwa indikator ini tidak termasuk pada indikator yang penting namun harapan pemasok pada kategori ini termasuk tinggi. Indikator lain pada prioritas utama namun memiliki kesenjangan yang berada dalam batas toleransi adalah kejelasan prosedur pelayanan (A), persyaratan pelayanan (B), dan respon terhadap keluhan dan saran pelanggan (L). Hal ini menyatakan walaupun rataan kepentingan menunjukkan penting, namun harapan dari pemasok terhadap ketiga indikator ini tidak tinggi. Secara keseluruhan, indikator yang berada di luar batas toleransi dan termasuk prioritas utama adalah kelengkapan alat 
laboratorium $(\mathrm{F})$ dan kecepatan pelayanan $(\mathrm{K})$, sedangkan harapan pada indikator $\mathrm{B}$ dan $L$ termasuk rendah walau berada pada kategori penting karena nilai kesenjangannya berada pada batas toleransi maksimal.

\section{Simpulan dan Saran}

Karakteristik responden pada rataan lama berlangganan secara keseluruhan adalah 11.6 tahun. Berdasarkan nilai indeks kepuasan konsumen, masing-masing kategori responden dan secara keseluruhan masih berada pada kategori puas terhadap jasa yang diberikan oleh laboratorium kimia karena memiliki nilai indeks kepuasan konsumen di atas $70 \%$. Pada kategori proses pabrik, tidak ada indikator yang termasuk prioritas utama dengan nilai kesenjangan di luar batas toleransi, namun masih terdapat indikator yang berada di luar batas toleransi yaitu indikator keselamatan, kesehatan, serta kerja $(\mathrm{N})$. Indikator yang perlu segera diperbaiki karena termasuk pada prioritas utama dan nilai kesenjangan di luar batas toleransi maksimal pada kategori tidak rutin adalah indikator kelengkapan alat (F). Sedangkan pada kategori pemasok adalah kelengkapan alat laboratorium $(F)$, kedisplinan petugas dalam melayani pelanggan $(\mathrm{H})$, dan kecepatan pelayanan $(\mathrm{K})$.

\section{Daftar Pustaka}

Azwar S. 2012. Reliabilitas dan Validitas Edisi 4. Yogyakarta (ID): Pustaka Pelajar. Churchill GA Jr. 2005. Dasar-dasar Riset Pemasaran Edisi Keempat Jilid 1. Andrianti, Yahya DK, Salim Emil, penerjemah; Saat S, Kristiaji WC, editor. Jakarta (ID): Penerbit Erlangga. Terjemahan dari: Basic Marketing Research, $4^{\text {th }}$ ed.

Hadi A. 2007. Pemahaman dan Penerapan ISO/IEC 17025:2005. Jakarta (ID): PT Gramedia Pustaka Utama.

Irawan H. 2002. Sepuluh Prinsip Kepuasan Pelanggan. Jakarta (ID): PT Elex Media Komputindo.

Kotler P, Keller KL. 2009. Manajemen Pemasaran Edisi Ketiga Belas Jilid 1. Sabran Bob, penerjemah; Maulana A, Hardani W, editor. Jakarta (ID): Erlangga. Terjemahan dari: Marketing Management, $13^{\text {th }}$ ed.

Kotler P, Keller KL. 2009. Manajemen Pemasaran Edisi Ketiga Belas Jilid 2. Sabran Bob, penerjemah; Maulana A, Hayati YR, editor. Jakarta (ID): Erlangga. Terjemahan dari: Marketing Management, $13^{\text {th }}$ ed.

Nasution MN. 2004. Manajemen Mutu Terpadu. Bogor (ID): Ghalia Indonesia.

Oktaviani RW, Suryana RN. 2006. Analisis Kepuasan Pengunjung dan Pengembangan Fasilitas Wisata Agro. J Agro Ekonomi [diunduh 2013 September 26]; Volume 24 No 1 Mei 2006: 41-58: Indonesia. Tersedia pada:http://pse.litbang.deptan.go.id/ind/pdffiles/JAE\%2024-1c.pdf.

Scheaffer RL, Mendelhall W, Ott L. 1990. Elementary Survey Sampling. Boston (US): PWS-KENT.

Sugiyono. 2011. Statistika untuk Penelitian. Bandung (ID): Alfabeta.

Zeithaml VA, Berry LL, Parasuraman A. 1985. A Conceptual Model of Service Quality and Its Implication for Future Research. J Marketing [diunduh 2013 Mei 
26];49(Fall 1985):41-50: Britania Raya (GB): Marketing Science Institute, Cambridge, MA. Tersedia pada: http://www.ff.ul.pt/FCT/PTDC/SAUESA/103946/2008/C22_FCT.pdf. 